\title{
New Challenges in Tunnel Fire Safety
}

\author{
Haukur Ingason*, SP Technical Research Institute of Sweden, Borås, Sweden \\ Haukur Ingason, Lund University, Lund, Sweden
}

The interest in tunnel fire safety and security has increased enormously in the last decade. I have personally been involved in research studies on tunnels since 1993, when the EUREKA 499 tests were carried out. Much has changed in the field since then, especially compared to our basic field understanding from that time and in light of the subsequent applications of engineering correlations for tunnel fire safety. Today, there are two important books available that provide a good, state-of-the-art overview of the field of tunnel fire safety: The Handbook of Tunnel Fire Safety [1], edited by Alan Beard and Richard Carvel, and the recently published Tunnel Fire Dynamics [2], written by Haukur Ingason, Ying Zhen Li, and Anders Lönnermark. Since EUREKA 499, a vast number of scientific articles on tunnel fire safety has been published, and the number is increasing continuously. It is important to maintain and strengthen our existing field knowledge and to present new, up-to-date research, when available.

The nine papers presented herein constitute a sound basis for future research in the field of tunnel fire safety, and it is my hope that this issue will offer an effective overview of the variety of research topics that are critical and relevant in the field. Much focus is on rolling stocks and their related design problems. There are also papers on fixed firefighting systems, construction, emergency response, explosions, and ventilation. The first paper addresses development of design fires - always a painstaking, delicate matter, yet each tunnel project's most crucial and essential task, as design fires determine how safe the tunnel's future users will be [3]. There are numerous methods available for administering a design fire; the method presented herein, which is focused on train carriages, is complicated but accurate, and considers many of the basic engineering parameters required for the setting of a design fire. The second paper considers a new method for risk assessment in rail tunnels; risk assessment is a process crucial in every tunnel project for determining actual risk [4]. The third paper considers one of the most challenging research areas in the field of underground fire safety: modelling and testing of users during evacuation in underground systems [5]. There is a significant shortage of data to apply to existing models, and the correlation between model structure and actual-scale experiments has been lacking. This paper narrows that gap and provides readers with new data for metro systems, which are actually among the most challenging fire safety designs today. The same could be said of firefighting

\footnotetext{
* Correspondence should be addressed to: Haukur Ingason, E-mail: haukur.ingason@sp.se
} 
in underground structures, which is presented in the fourth paper. Evacuation and firefighting overlap considerably, as one must evacuate from the fire while another must find an entryway into a fire and determine the best manner of fighting it; along the way, the two eventually meet. Firefighters must be adequately prepared and supplied if they are to execute both tasks - saving evacuees and fighting the fire. This fourth paper presents new data on capacity, in terms of how quickly the firefighters can approach, but also in terms of which tactics and techniques work best in deep and lengthy tunnels - excellent information, and useful for both firefighters and engineers [6]. Fixed firefighting systems are proposed for use in road tunnels (but not for rail tunnels) to render the environment safer for firefighters. The fifth paper presents new, large-scale tests implementing a large drop, sidewall sprinkler system; this is a unique system, and the results have already been implemented in infrastructure projects in Sweden [7]. This paper's research stresses the importance of testing the sprinkler system before making decisions on its use. Model scale models and full-scale test data were both used with impressive results. The sixth paper presents unique results from full-scale tests with trains; such information is essential and much-appreciated by engineers and researchers [8]. In the seventh paper, data is presented on one of the most common objects found in road tunnels: rubber tires [9]. Such data is somewhat rare, despite a significant need and demand for it; thus, it is exciting to be able to include such a paper in this issue. The eighth paper presents a method for estimating the dynamic forces to which underground structures can be exposed; there is a demand for more papers on this topic - presenting both experimental results and theoretical concerns [10]. The last paper addresses problems that may occur during the design of a ventilation system; the paper focuses on throttling effects, which has to do with flow resistance as a result of the fire and the tunnel's geometry [11]. The authors consider these throttling effects to be a significant problem and present the solution to them in this paper.

A number of related subjects still require further focus from the research community. Presenting papers based on FDS simulations is no longer acceptable, lest new methods be presented. Critical velocities are no longer a priority area for research, as much has already been published on the issue. Rather, studies on backlayering are of greater interest, and further attention needs to be paid to heat losses from gases and smoke and the effects of empirical correlations. As new energy carriers find their way into tunnels, they will, likewise, require further study. Naturally, the primary foci of such future research should be on the fire's behaviours and on risks for tunnel users and firefighters.

There is a great future for tunnel fire safety and security, but the knowledge base must increase apace with the growing number of new tunnels being constructed worldwide, and it is important to protect our complicated and fragile underground infrastructures. I hope this special issue will provide you with new information and enhanced expertise in our collective attempt to reduce the knowledge gap. 


\section{References}

1. Beard AN, Carvel RO (2012) Handbook of tunnel fire safety-Second Edition. ICE Publishing, London

2. Ingason H, Li YZ, Lönnermark A (2015) Tunnel fire dynamics. Springer, New York

3. Li YZ, Ingason H (2015) A new methodology of design fires for train carriages based on exponential curve method. Fire Technol. doi:10.1007/s10694-015-0464-3

4. Weyenberge BV, Deckers X, Caspeele R, Merci B (2015) Development of a risk assessment method for life safety in case of fire in rail tunnels. Fire Technol. doi:10.1007/ S10694-015-0469-Y

5. Fridolf K, Nilson D, Frantzich H (2015) Evacuation of a metro train in an underground rail transportation system: flow rate capacity of train exits, tunnel walking speeds and exit choice. Fire Technol. doi:10.1007/S10694-015-0471-4

6. Palm A, Kumm M, Ingason H (2015) Full scale firefighting tests in the Tistbrottet mine. Fire Technol. doi:10.1007/s10694-015-0476-Z

7. Ingason H, Li YZ, Appel G, Lundström U, Becker C (2015) Large scale tunnel fire tests with large droplet water-based fixed fire fighting system. Fire Technol. doi:10.1007/s10694-015-0479-9

8. Lee DH, Park WH, Hwang J, Hadjisophocleous G (2015) Full-scale fire test of an intercity train car. Fire Technol. doi:10.1007/S10694-015-0482-1

9. Alvares N, Hasegawa H, Staggs K (2015) Ignition, heat release rate and suppression of elastomeric materials. Fire Technol. doi:10.1007/S10694-015-0483-0

10. Stolz A, Ruiz-Ripoll ML (2015) Experimental and computational characterization of dynamic loading and structural resistance of tunnels in blast scenarios. Fire Technol. doi:10.1007/S10694-015-0496-8

11. Vaitkevicius A, Colella F, Carvel R (2015) Investigating the throttling effect in tunnel fires. Fire Technol. doi:10.1007/S10694-015-0512-Z 